\title{
Efeito da Substituição do Feldspato por Filito sobre a Deformação Piroplástica de Massas de Porcelanato Esmaltado
}

\author{
Miguel Y. Hernández-Sánchez ${ }^{a, b}$, Suelen Nastria,b, Fábio G. Melchiades ${ }^{c}$, Anselmo O. Boschia,b* \\ a Programa de Pós-graduação em Ciência e Engenharia de Materiais - PPGCEM, Universidade Federal de São Carlos - \\ UFSCar, São Carlos, SP, Brasil \\ ${ }^{b}$ Laboratório de Revestimentos Cerâmicos - LaRC, Departamento de Engenharia de Materiais - DEMa, Universidade Federal \\ de São Carlos - UFSCar, São Carlos, SP, Brasil \\ ${ }^{c}$ Centro de Revestimentos Cerâmicos - CRC, São Carlos, SP, Brasil \\ *e-mail: anselmo.ufscar@gmail.com
}

\begin{abstract}
Resumo
O fenômeno de deformação piroplástica ocorre frequentemente em produtos de alta vitrificação como os porcelanatos. A deformação do formato provocada por forças de gravidade, devido ao próprio peso da peça cerâmica, durante o ciclo térmico está relacionado ao volume de fase líquida e/ou à viscosidade da mesma no durante a queima. O desenvolvimento de novos produtos com grandes dimensões e espessuras menores contribuiu para o aumento da preocupação com a deformação piroplástica. O objetivo deste trabalho foi avaliar comparativamente o efeito da substituição do feldspato por filito em massas de porcelanato esmaltado sobre a deformação piroplástica. Os resultados obtidos indicam que, nas condições deste estudo, a substituição do feldspato pelo filito reduz significativamente a deformação piroplástica da massa. A análise dos resultados sugere que tal diminuição se deve principalmente ao fato de que a viscosidade da fase líquida formada pela fusão do feldspato é consideravelmente menor do que a resultante da fusão da mica muscovita, que o volume de líquido formato na máxima temperatura também é significativamente maior na massa contendo feldspato e que a fusão do feldspato se dá a uma temperatura inferior à da mica muscovita.
\end{abstract}

Palavras-chave: deformação piroplástica, porcelanato esmaltado, filitos.

\section{Introdução}

A produção, de porcelanatos tem crescido consideravelmente no mundo todo [1]. Uma das características utilizadas para classificar os revestimentos cerâmicos é a absorção de água. Segundo esse critério a absorção de água dos porcelanatos técnicos e esmaltados deve ser inferior a 0,1 e $0,5 \%$, respectivamente [2]. Para alcançar absorções de água tão baixas, as massas utilizadas na fabricação dessa tipologia de produto contêm elevados teores de fundentes. De um modo geral, as massas utilizadas na fabricação de porcelanatos são baseadas no clássico triaxial cerâmico e utilizam o feldspato como fundente. Massas desse tipo foram exaustivamente estudadas $[3,4,5]$.

O fenômeno da deformação piroplástica tem se tornado especialmente importante na indústria de revestimentos cerâmicos por vários motivos: 1) o aumento da produção de porcelanatos, 2) as peças serem cada vez maiores e de menor espessura, 3) dos formatos retangulares, 4) a utilização de fundentes enérgicos e matérias-primas não plásticas com granulometria fina. A combinação desses fatores tem contribuído para o aumentar consideravelmente a preocupação com a deformação piroplástica dos porcelanatos [6,7].

No Brasil, por motivos diversos (custo, disponibilidade, etc.) [8] a maioria das indústrias que produzem porcelanato esmaltado substituíram o feldspato pelo filito. Muito embora o filito venha sendo utilizado como fundente há muitos anos nas indústrias cerâmicas brasileiras, não se tem notícia de estudos que avaliem as consequências da substituição do feldspato pelo filito em massas de porcelanato. Nesse cenário, o objetivo deste trabalho foi avaliar comparativamente os efeitos da substituição do feldspato por filito sobre a deformação piroplástica em massas de porcelanato esmaltado.

\subsection{Deformação piroplástica}

A deformação piroplástica depende fundamentalmente do volume e das características da fase líquida na temperatura de queima e das características da estrutura porosa na qual a mesma é alojada [9].

O volume de fase líquida é determinado principalmente pelo teor de fundente na massa e pela máxima temperatura de queima.

Dentre as características da fase líquida, a viscosidade é uma das mais importantes. A viscosidade da fase líquida depende fundamentalmente da sua composição química e da temperatura. É importante mencionar que durante a queima a fase líquida pode interagir com os demais materiais presentes e dissolve-los parcialmente, o que resulta na alteração da sua composição química e consequentemente da sua viscosidade a uma determinada temperatura.

Esses aspectos, volume e viscosidade da fase líquida, são fundamentais no desenvolvimento da microestrutura final 
dos porcelanatos e, consequentemente, das características técnicas dos mesmos [5]. Vale lembrar que cerâmicas de mesa e porcelanas são sinterizadas em ciclos longos (acima de 3 horas), ou seja, mais longos do que os ciclos utilizados na queima de porcelanatos (40 a 60 minutos). Portanto, os inúmeros estudos sobre essas tipologias de produto não se aplicam diretamente aos porcelanatos.

\section{Materiais e Métodos}

Como pode ser visto na Tabela 1, a estratégia utilizada para avaliar comparativamente o efeito da substituição do feldspato pelo filito sobre a deformação piroplástica foi o desenvolvimento de uma massa contendo feldspato como fundente e outra em que o teor de feldspato, em peso, foi substituído por um filito. As matérias-primas selecionadas são comumente utilizadas na fabricação de porcelanatos.

As Tabelas 2 e 3 apresentam as composições químicas e mineralógicas dos fundentes utilizados. A composição mineralógica qualitativa foi estimada por análise racional [10].

Após a dosagem, cada massa foi preparada por via úmida: moagem a úmido das matérias-primas em moinho de bolas com uma razão massa seca /água de $52 \%$ e $0,75 \%$ de silicato de sódio como defloculante. O tempo de moagem foi ajustado para que o resíduo fosse inferior a $2 \%$ em peneira Tyler 250 (ABNT \#230, abertura de $63 \mu \mathrm{m})$. A seguir as barbotinas foram secas em estufa a $110^{\circ} \mathrm{C}$ durante 24 horas, desagregadas em almofariz, granuladas em peneiras com adição de 7,0\% de água e descansaram por no mínimo 24 horas em recipiente selado, para garantir uma umectação homogênea. Posteriormente, corpos de provas na forma de barrinhas $(60 \mathrm{~mm} \times 20 \mathrm{~mm})$ foram

Tabela 1. Formulação das massas utilizadas.

\begin{tabular}{ccc}
\hline $\begin{array}{c}\text { Matérias- } \\
\text { primas (\%) }\end{array}$ & mFilito & mFeldspato \\
\hline Argilas & 42 & 42 \\
Talco & 6 & 6 \\
Calcário & 2 & 2 \\
Filito & $\mathbf{5 0}$ & - \\
\hline Feldspato & - & $\mathbf{5 0}$ \\
\hline
\end{tabular}

obtidos por prensagem uniaxial em uma prensa automática NANETTI PRESS EA, sob pressões de $260 \mathrm{Kgf} / \mathrm{cm}^{2}$ a $400 \mathrm{Kgf} / \mathrm{cm}^{2}$. Após secagem os corpos de prova foram queimados em forno a rolos de laboratório com ciclo de queima de 40 minutos em distintas temperaturas para a confecção das curvas de gresificação.

Usualmente a deformação piroplástica é quantificada pelo índice de piroplasticidade (IP) a partir da medida da curvatura após queima de um corpo de prova apoiado sobre dois suportes refratários, como mostra a Figura 1, e calculado por meio da equação 1. Para isso, inicialmente foram levantadas as curvas de gresificação das duas massas para determinar a temperatura de queima necessária para que a absorção de água dos corpos de prova fosse de $1 \%$.

$$
I P=\frac{4 * h^{2} * S}{3 * L^{4}}
$$

Onde:

IP: representa o índice de piroplasticidade $\left(\mathrm{cm}^{-1}\right)$;

$\mathrm{S}$ : representa a deformação máxima $(\mathrm{cm})$;

h: representa a espessura da peça $(\mathrm{cm})$; e,

L: a distância entre os suportes refratários $(\mathrm{cm})$.

Com base na composição química teórica dos minerais responsáveis pelo surgimento da fase líquida (Tabela 4), albita e ortoclásio no feldspato e mica muscovita no filito, a viscosidade das mesmas foi estimada através do modelo de Giordano [11].

\section{Resultados e Discussão}

As Figuras 2 e 3 apresentam, respectivamente, a variação da absorção de água e retração linear de queima com a temperatura das massas contendo feldspato e filito prensadas a duas pressões, 260 e $400 \mathrm{Kgf} / \mathrm{cm}^{2}$.

No que se refere à variação da absorção de água, as temperaturas necessárias para atingir os $0,5 \%$, máximo valor admissível pela norma para essa tipologia de produto [2], foram $1195^{\circ} \mathrm{C} \mathrm{e} 1235^{\circ} \mathrm{C}$ para a mFeldspato e mFilito, respectivamente, independentemente da pressão de compactação. A inclinação das curvas das duas massas é significativamente diferente, com a absorção de água da

Tabela 2. Composição química dos fluxos utilizados.

\begin{tabular}{cccccccccccc}
\hline $\begin{array}{c}\text { Matérias- } \\
\text { primas }\end{array}$ & \multicolumn{10}{c}{ Composição química (\% wt) } \\
\cline { 2 - 12 } & $\mathbf{S i O}_{2}$ & $\mathbf{A l}_{2} \mathbf{O}_{3}$ & $\mathbf{F e}_{2} \mathbf{O}_{3}$ & $\mathbf{C a O}$ & $\mathbf{M g O}$ & $\mathbf{T i O}_{2}$ & $\mathbf{P}_{2} \mathbf{O}_{\mathbf{5}}$ & $\mathbf{N a}_{2} \mathbf{O}$ & $\mathbf{K}_{2} \mathbf{O}$ & $\mathbf{M n O}$ & P.F.* $^{*}$ \\
\hline Filito & 74,2 & 16,2 & 0,98 & 0,03 & 1,01 & 0,76 & 0,05 & $\mathbf{0 , 1 8}$ & $\mathbf{3 , 3 1}$ & $<0,01$ & 4,12 \\
Feldspato & 72,6 & 15,3 & 0,08 & 0,19 & $<0,1$ & $<0,01$ & 0,17 & $\mathbf{3 , 3 1}$ & $\mathbf{7 , 6 7}$ & $<0,01$ & 0,29 \\
\hline
\end{tabular}

*PF = perda ao fogo

Tabela 3. Composição mineralógica qualitativa dos fluxos utilizados, estimada por análise racional [10].

\begin{tabular}{ccccccccc}
\hline $\begin{array}{c}\text { Matérias- } \\
\text { primas }\end{array}$ & $\begin{array}{c}\text { Caulinita } \\
\mathbf{( \% )}\end{array}$ & $\begin{array}{c}\text { Mica } \\
\text { muscovita } \\
(\%)\end{array}$ & $\begin{array}{c}\text { Quartzo } \\
(\mathbf{\%})\end{array}$ & $\begin{array}{c}\text { Ilita } \\
(\mathbf{\%})\end{array}$ & $\begin{array}{c}\text { Microclínio } \\
\mathbf{( \% )}\end{array}$ & $\begin{array}{c}\text { Albita } \\
\mathbf{( \% )}\end{array}$ & $\begin{array}{c}\text { Hematita } \\
(\mathbf{\%})\end{array}$ & $\begin{array}{c}\text { Outros } \\
\mathbf{( \% )}\end{array}$ \\
\hline Filito & 13,8 & $\mathbf{2 8 , 0}$ & 55,1 & - & - & - & 1,0 & 2,2 \\
Feldspato & - & - & 23,1 & 5,9 & $\mathbf{4 2 , 2}$ & $\mathbf{2 8 , 0}$ & 0,1 & 0,8 \\
\hline
\end{tabular}


Tabela 4. Composição química teórica da mica muscovita e do feldspato.

\begin{tabular}{|c|c|c|c|c|c|c|}
\hline Composição Química (\%) & $\mathrm{SiO}_{2}$ & $\mathrm{Al}_{2} \mathrm{O}_{3}$ & $\mathrm{Fe}_{2} \mathrm{O}_{3}$ & $\mathrm{~K}_{2} \mathrm{O}$ & $\mathrm{Na}_{2} \mathrm{O}$ & $\mathrm{PF}^{*}$ \\
\hline $\begin{array}{c}\text { Muscovita } \\
\mathrm{KAl}_{2}[\mathrm{Si} 3 \mathrm{Al}] \mathrm{O}_{10}(\mathrm{OH}, \mathrm{F})_{2}\end{array}$ & 45,21 & 38,36 & - & 11,81 & - & 4,07 \\
\hline Muscovita sem PF & 47,40 & 40,22 & - & 12,38 & - & - \\
\hline $\begin{array}{c}\text { Ortoclásio } \\
\left(\mathrm{KAlSi}_{3} \mathrm{O}_{8}\right) 42,2 \%\end{array}$ & 64,80 & 18,40 & - & 16,90 & - & - \\
\hline $\begin{array}{c}\text { Albita } \\
\left(\mathrm{NaAlSi}_{3} \mathrm{O}_{8}\right) 28,0 \%\end{array}$ & 68,70 & 19,80 & - & - & 11,82 & - \\
\hline Mistura de Feldspatos & 66,35 & 18,84 & - & 10,16 & 4,72 & - \\
\hline
\end{tabular}
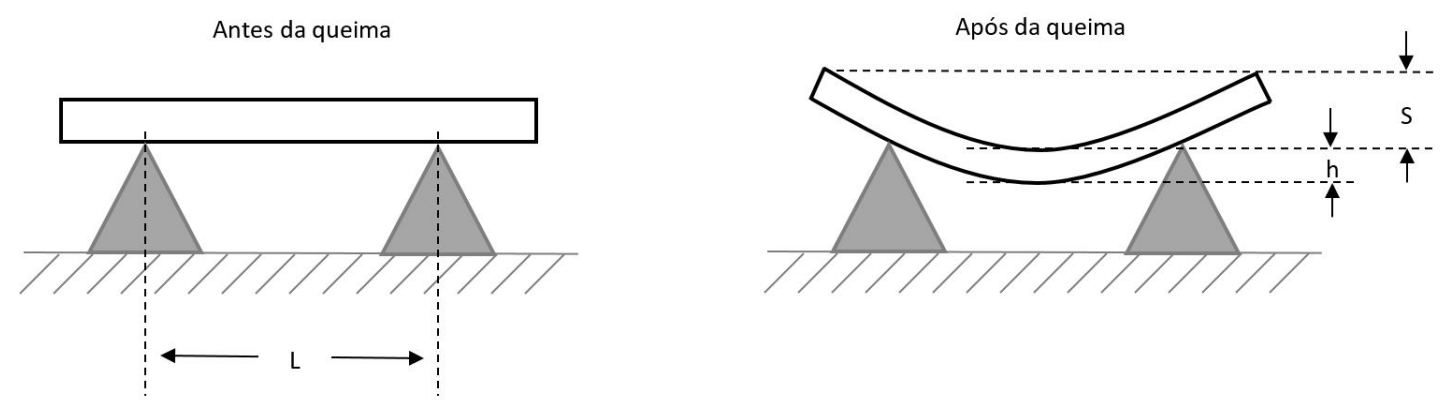

Figura 1. Posicionamento do corpo de prova antes e após a queima para ensaio de piroplasticidade.

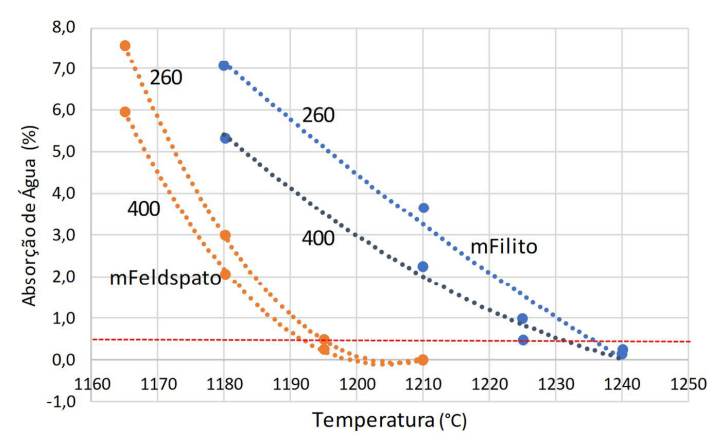

Figura 2. Variação da absorção de água das massas contendo feldspato e filito prensadas a duas pressões, 260 e $400 \mathrm{Kgf} / \mathrm{cm}^{2}$ com a temperatura de queima. A linha vermelha tracejada corresponde à exigência da norma para essa tipologia de produto, porcelanato esmaltado.

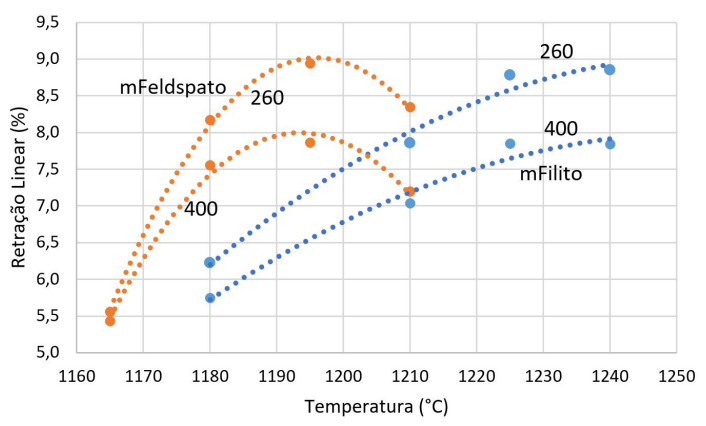

Figura 3. Variação da retração linear de queima com a temperatura das massas contendo feldspato e filito prensadas a duas pressões, 260 e $400 \mathrm{Kgf} / \mathrm{cm}^{2}$.
mFeldspato diminuindo mais rapidamente do que a mFilito. Como esperado, o aumento da pressão de compactação resultou em uma redução da absorção de água para as mesmas temperaturas de queima.

A Figura 3 apresenta a variação da retração linear de queima com a temperatura das duas massas, mFeldspato e mFilito, para corpos de prova prensados a 260 e $400 \mathrm{Kgf} / \mathrm{cm}^{2}$. Pode-se notar que as curvas representando as duas massas também são bastante diferentes. A $1195{ }^{\circ} \mathrm{C}$ a massa mFeldspato atingiu a máxima densificação e sobrequeimou acima dessa temperatura, ao passo que a mFilito não apresentou sinais de sobrequeima até $1240^{\circ} \mathrm{C}$. Apesar das diferenças de densidade dos compactos antes da queima (Tabela 5), a retração até a temperatura em que os corpos de prova das duas massas alcançaram a absorção de água de $0,5 \%$ são bastante similares, sugerindo que o volume de poros fechados da mFeldspato, de menor densidade aparente, é maior do que o da mFilito. A inclinação das curvas também é consideravelmente diferente com a $\mathrm{mFeldspato}$ apresentando uma variação maior da retração linear com a temperatura, em relação a mFilito.

O aumento da pressão de compactação, como esperado, reduziu a retração linear de queima.

A Tabela 5 apresenta algumas características das massas estudadas. Pode-se notar que a $260 \mathrm{Kgf} / \mathrm{cm}^{2}$ as densidades das duas massas são praticamente idênticas ao passo que ao se aumentar a pressão de compactação para $400 \mathrm{Kgf} / \mathrm{cm}^{2}$ a densidade aparente média dos compactos da mFeldspato é inferior à dos compactos da mFilito. Isso provavelmente se deve ao fato de que a distribuição de tamanho das partículas da mFilito é mais larga, o que beneficia sua compacidade. Pode-se notar também que o 
Tabela 5. Características das massas porcelânicas.

\begin{tabular}{ccccc}
\hline Massas & mFilito & \multicolumn{2}{c}{ mFeldspato } \\
\hline $\begin{array}{c}\text { Pressão de compactação a verde } \\
\left(\mathrm{Kgf} / \mathrm{cm}^{2}\right)\end{array}$ & 260 & 400 & 260 & 400 \\
$\begin{array}{c}\text { Densidade aparente } \\
\left(\mathrm{Kg} / \mathrm{cm}^{2}\right)\end{array}$ & 1,79 & 1,90 & 1,78 & 1,85 \\
$\begin{array}{c}\text { Temperatura de máxima densificação } \\
\left({ }^{\circ} \mathrm{C}\right)\end{array}$ & $\mathrm{XXXX}$ & $\mathrm{XXXX}$ & 1195 & 1196 \\
\hline
\end{tabular}

aumento da pressão de compactação reduz a temperatura de máxima densificação da mFilito.

A Figura 4 apresenta graficamente os índices de piroplasticidade (IP) das duas massas, mFilito e mFeldspato compactadas a duas pressões, 260 e $400 \mathrm{Kgf} / \mathrm{cm}^{2}$. O índice de piroplasticidade da massa mFeldspato é consideravelmente maior do que o da mFilito. Cabe mencionar que, diferentemente do que consta na literatura, a variação da pressão de compactação, e consequentemente da densidade aparente dos compactos, não afetou significativamente o índice de piroplaticidade.

Assumindo que as estruturas porosas dos compactos, nas quais a fase líquida será alojada, sejam similares e considerando que a deformação piroplástica no caso de massas porcelânicas ocorre por meio do mecanismo de fluxo viscoso [12], no qual a deformação ocorre por processos de difusão [13] e que duas das mais relevantes características responsáveis pela mesma são a viscosidade e o volume da fase líquida, buscou-se métodos para estimar essas características.

Para estimar a viscosidade das fases líquidas formadas a partir da fusão da mistura de albita e ortoclásio, na mFeldspato, e da mica muscovita, na mFilito utilizou-se o modelo de Giordano [11]. Os resultados são apresentados na Figura 5.

A viscosidade estimada da fase líquida formada a partir da fusão da mistura de feldspatos é significativamente menor do que a formada pela fusão da mica muscovita. Essa diferença diminui com o aumento da temperatura. Portanto, no que se refere a viscosidade da fase líquida, a maior taxa de densificação (Figuras 2 e 3) da mFeldspato em relação a mFilito era esperada. Entretanto, a grande diferença entre as taxas de densificação não é completamente justificada pela diferença entre as viscosidades das fases líquidas e é bem provável que outros fatores também sejam responsáveis pela mesma.

O emprego do modelo de Giordano para estimar a viscosidade da fase líquida requer cautela. Trata-se de um modelo empírico baseado na equação de Vogel-Fulcher-Tammann. O modelo foi desenvolvido inicialmente para vidros a partir de um grande número de resultados experimentais e posteriormente refinado para fundidos multicomponentes anidros e de silicatos $[11,12]$. Assim sendo, o modelo não leva em consideração as alterações da composição química decorrentes da interação entre a fase líquida e as demais fases presentes. Além disso, os dados utilizados para alimentar o modelo se basearam nas composições químicas teóricas dos minerais fundentes e não em medidas experimentais das composições químicas das fases líquidas. Entretanto, a

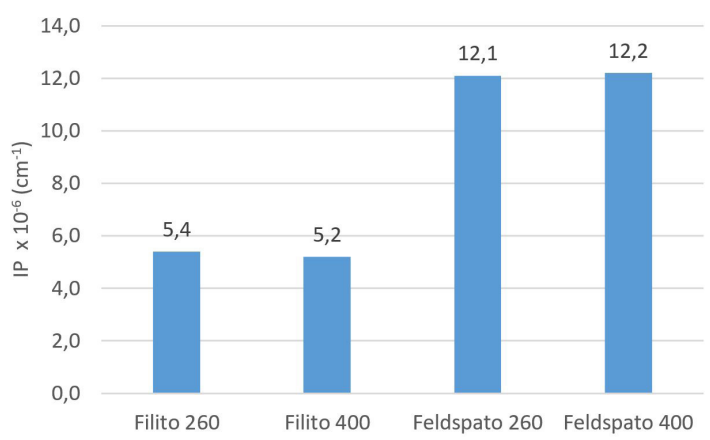

Figura 4. Índice de piroplasticidade (IP) das massas mFilito e mFeldspato compactadas a duas pressões, 260 e $400 \mathrm{Kgf} / \mathrm{cm}^{2}$.

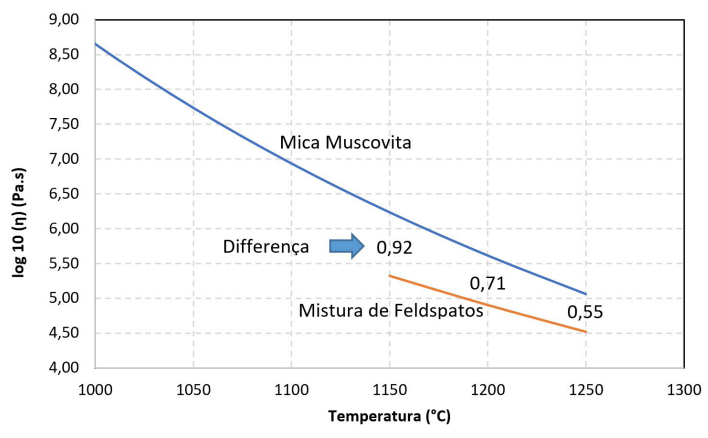

Figura 5. Variação da viscosidade da fase vítrea formada a partir da fusão dos minerais fundentes, albita e ortoclásio no feldspato e mica muscovita no filito, com a temperatura, estimada através do modelo de Giordano [11].

compatibilidade entre os comportamentos observados (Figuras 2 e 3 ) e as previsões do modelo justificam sua inclusão neste.

No que se refere ao volume da fase líquida, o teor de minerais fundentes, albita + ortoclásio na mFeldspato e mica muscovita na mFilito, é bastante diferente nas duas massas, sendo consideravelmente maior na mFeldspato. Além disso o teor de $\mathrm{Na}_{2} \mathrm{O}+\mathrm{K}_{2} \mathrm{O}$ no feldspato é consideravelmente maior do que no filito: 11,0 e $3,5 \%$, respectivamente. $\mathrm{O}$ teor mais baixo de $\mathrm{Na}_{2} \mathrm{O}+\mathrm{K}_{2} \mathrm{O}$ no filito se deve ao fato de que, como apresentado na Tabela 3 , nesse mineral esses óxidos estão presentes na mica muscovita que representa $28 \%$ da composição do mineral ao passo que no feldspato o microclínio + albita representam 70,2\%. Portanto, a adição de $50 \%$ em peso dessas matérias-primas, filito e feldspato, aporta às massas teores significativamente 
diferentes de fundentes. Assim sendo, é de se esperar que o teor de fase líquida formado na mFeldspato durante a queima seja substancialmente maior dos que na mFilito, o que é compatível com a diferença entre os índices de piroplasticidade apresentados na Figura 4.

Outro aspecto que pode ter afetado os resultados é o fato de que durante o aquecimento a mistura de feldspatos se funde antes da mica, o que faz com que a fase líquida formada pela fusão dos feldspatos tenha mais tempo durante o aquecimento para escoar e contribuir para aumentar o índice de piroplasticidade.

Para finalizar é importante mencionar que as formulações usadas neste trabalho foram desenvolvidas com o objetivo de permitir comparar o comportamento das massas durante a queima e os índices de piroplasticidade. Para conseguir isso a formulação da mFilito desenvolvida não é representativa das utilizadas industrialmente.

As formulações utilizadas na produção de porcelanatos esmaltados contendo feldspato ou filito como fundentes são diferentes e as temperaturas de queima são similares.

De um modo geral as formulações com feldspato evitam o uso de teores significativos de talco e minerais de cálcio, principalmente para evitar problemas de deformação piroplástica. Por outro lado, as formulações que utilizam o filito como fundente usualmente contém talco e minerais que contém cálcio. Esta combinação proporciona às massas com filito uma fusibilidade similar à das que contém feldspato, e consequentemente temperaturas de queima similares, sem aumentar de maneira expressiva a tendência à deformação piroplástica. De um modo geral o índice de piroplasticidade das massas industriais que utilizam filito é menor do que o das que usam feldspato.

\section{Conclusão}

Nas condições deste estudo, a substituição do feldspato pelo mesmo teor de filito em uma massa de porcelanato esmaltado reduziu consideravelmente o índice de piroplasticidade da mesma. Algumas possíveis explicação para isso são:

1) a menor viscosidade da fase líquida formada pela fusão do feldspato em relação à formada pela fusão da mica muscovita;

2) o maior volume de fase líquida formado durante a queima da formulação contendo feldspato em relação à contendo filito;

3) a menor temperatura de fusão do feldspato em relação à mica muscovita.

\section{Agradecimentos}

O presente trabalho foi realizado com apoio da Coordenação de Aperfeiçoamento de Pessoal de Nível Superior - Brasil (CAPES) - Código de Financiamento 001. Ao Programa de Pós-Graduação em Ciência e Engenharia de Materiais (PPGCEM) da Universidade Federal de São Carlos (UFSCar) e ao Laboratório de Revestimentos Cerâmicos (LaRC).

\section{Referências}

1. BARALDI, LUCA; ACIMAC. World production and consumption of ceramic tiles. Tile International, v. 3, p. 42-48, 2017. ISSN 2039-8301. Disponivel em: $<$ https://issuu. com/tiledizioni/docs/000_112_tile_international_3_2017>. Acesso em: 08 Mar. 2018.

2. ASSOCIAÇÃO BRASILEIRA DE NORMAS TÉCNICAS. NBR 15463: placas cerâmicas para revestimento - porcelanato. Rio de Janeiro: ABNT, 2013.

3. BARBA, A. et al. Materias Primas para la fabricación de soportes de baldosas cerámicas. $1^{a}$. ed. Castellón: Instituto de Tecnología Cerámica - AICE, 1997. 292 p. ISBN 84-923176-6-3.

4. DONDI, M.; RAIMONDO, M.; ZANELLI, C. Sintering mechanisms of porcelain stoneware tiles. In: PROCEEDINGS SINTERING 2003 International Conference on the Science, Technology \& Applications of Sintering, September 15 - 17, Penn State University. Pennsylvania: The Materials Research Institute and The Center for Innovative Sintered Products, 2003.

5. MARTÍN-MÁRQUEZ, J.; RINCÓN, J. M.; ROMERO, M. Effect of firing temperature on sintering of porcelain stoneware tiles. Ceramics International, v. 34, n. 8, p. 1867-1873, dez. 2008. Disponivel em: <https://doi.org/10.1016/j. ceramint.2007.06.006>.

6. MELCHIADES, F. G. et al. Deformação piroplástica de porcelanatos. Cerâmica Industrial, v. 19, n. 1, p. 13-17, 2014. Disponivel em: <http://dx.doi.org/10.4322/cerind.2014.059>.

7. SÁNCHEZ, E. et al. Deformación de cocción en gres porcelánico de gran formato. Efecto de las variables composicionales y de proceso. In: _ XV Congreso Mundial de la Calidad del Azulejo y del Pavimento Cerámico - QUALICER'18. Castellón: QUALICER, 2018. p. 1-17. Ponencia 17.

8. CABRAL JUNIOR, M. Matérias-primas para a produção de porcelanato no Brasil: cenário atual, demandas e oportunidades. São Paulo: Expo Revestir, 2018. Disponivel em: <http:// escriba.ipt.br/pdf/175099.pdf>. Acesso em: 02 jul. 2018. Palestra. 36 slides.

9. CONSERVA, L. R. D. S. et al. Pyroplastic deformation of porcelain stoneware tiles: Wet vs. dry processing. Journal of the European Ceramic Society, n. 37, p. 333-342, 2017. Disponivel em: <http://dx.doi.org/10.1016/j. jeurceramsoc.2016.08.015>.

10. COELHO, C.; ROQUEIRO, N.; HOTZA, D. Rational mineralogical analysis of ceramics. Materials Letters, v. 52, n. 6, p. 394-398, fev. 2002. Disponivel em: <http:// dx.doi.org/10.1016/S0167-577X(01)00429-3>.

11. GIORDANO, D.; RUSSELL, J. K.; DINGWELL, D. B. Viscosity of magmatic liquids: A model. Earth and Planetary Science Letters, v. 271, p. 123-134, 2008. Disponivel em: $<$ http://dx.doi.org/10.1016/j.eps1.2008.03.038>.

12. CONTE, S. et al. High temperature viscosity of porcelain stoneware bodies. In: XV Congreso Mundial de la Calidad del Azulejo y del Pavimento Cerámico - QUALICER'18. Castellón: QUALICER, 2018. p. 1-9. Ponencia 16.

13. CONSERVA, L. R. D. S. et al. Deformação Piroplástica de Porcelanatos: Influência da Rota de Fabricação (Via Úmida $\times$ Via Seca). Cerâmica Industrial, v. 20, n. 4, p. 7-15, Jul/Ago 2015. Disponivel em: <http://dx.doi.org/10.4322/ cerind.2015.032>. 